\title{
Trends in utilization and costs of BRCA testing among women aged 18-64 years in the United States, 2003-2014
}

\author{
Zhuo Chen, $\mathrm{PhD}^{1,2,3}$, Katherine Kolor, $\mathrm{PhD}^{1}$, Scott D. Grosse, PhD ${ }^{4}$, Juan L. Rodriguez, MPH, $\mathrm{MS}^{5}$, \\ Julie A. Lynch, PhD ${ }^{6,7}$, Ridgely Fisk Green, $\mathrm{PhD}^{1,8}$, W. David Dotson, PhD ${ }^{1}, \mathrm{M}$. Scott Bowen, MPH ${ }^{1}$ and \\ Muin J. Khoury, MD, PhD ${ }^{1}$
}

Purpose: We examined 12-year trends in BRCA testing rates and costs in the context of clinical guidelines, national policies, and other factors.

Methods: We estimated trends in BRCA testing rates and costs from 2003 to 2014 for women aged 18-64 years using private claims data and publicly reported revenues from the primary $B R C A$ testing provider.

Results: The percentage of women with zero out-of-pocket payments for BRCA testing increased during 2013-2014, after 7 years of general decline, coinciding with a clarification of Affordable Care Act coverage of BRCA genetic testing. Beginning in 2007, family history accounted for an increasing proportion of women with $B R C A$ tests compared with personal history, coinciding with $B R C A$ testing guidelines for primary care settings and direct-to-consumer advertising campaigns. During 2013-2014,
$B R C A$ testing rates based on claims grew at a faster rate than revenues, following 3 years of similar growth, consistent with increased marketplace competition. In 2013, BRCA testing rates based on claims increased $57 \%$, compared with $11 \%$ average annual increases over the preceding 3 years, coinciding with celebrity publicity.

Conclusion: The observed trends in BRCA testing rates and costs are consistent with possible effects of several factors, including the Affordable Care Act, clinical guidelines and celebrity publicity.

Genet Med advance online publication 21 September 2017

Key Words: Affordable Care Act; BRCA testing costs; $B R C A$ testing; $B R C A$ testing utilization; hereditary breast and ovarian cancer

\section{INTRODUCTION}

Genetic testing for mutations in the breast cancer 1 (BRCA1) and breast cancer 2 (BRCA2) genes to identify women at increased risk for breast and ovarian cancer who could benefit from preventive interventions has been supported by evidence-based guidelines for over a decade. ${ }^{1}$ Moreover, for women affected by these cancers, knowing whether they have a BRCA mutation can affect their treatment decisions, including surgical and drug treatments. ${ }^{2,3}$ Current guidelines from the US Preventive Services Task Force (USPSTF), the National Comprehensive Cancer Network, and others outline personal and/or family history screening criteria that can be used in the primary care or specialty setting to identify patients at increased risk for pathogenic BRCA mutations. ${ }^{1,2,4-10}$

Women with pathogenic BRCA mutations have an estimated $45-65 \%$ risk of breast cancer and a $17-39 \%$ risk of ovarian cancer by age 70 , as compared with a $7 \%$ risk of breast cancer and $0.6 \%$ risk of ovarian cancer by age 70 in the general population. ${ }^{1,11}$ Timely ascertainment of these women allows for preventive interventions, including enhanced screening, chemoprevention, or prophylactic surgery to remove the breasts and/or ovaries, that can significantly decrease morbidity and mortality. Prophylactic mastectomy can reduce the risk of breast cancer by $85-100 \%$, and prophylactic oophorectomy can reduce the risk of ovarian cancer by $69-100 \%$ and breast cancer by $37-100 \% .{ }^{1}$

$B R C A$ test utilization and costs in the United States may be influenced by numerous factors, such as increased education, awareness, professional society recommendations, clinical guidelines, scientific evidence, evolving technology, national policies and celebrity endorsements. ${ }^{12-14} \mathrm{~A}$ recent example is the Patient Protection and Affordable Care Act (ACA), which requires most private health plans to provide in-network coverage without cost-sharing (such as copayments, deductibles, or coinsurance) for BRCA genetic counseling as a preventive service for women whose family history is associated with an increased risk for deleterious $B R C A$ mutations in accordance with the USPSTF recommendation. ${ }^{15-17}$ A potential

${ }^{1}$ Office of Public Health Genomics; Center for Surveillance, Epidemiology and Laboratory Services, Centers for Disease Control and Prevention (CDC), Atlanta, Georgia, USA; ${ }^{2}$ Department of Health Policy and Management, College of Public Health, University of Georgia, Athens, Georgia, USA; ${ }^{3}$ School of Economics, University of Nottingham, Ningbo, China; ${ }^{4}$ National Center on Birth Defects and Developmental Disabilities, CDC, Atlanta, Georgia, USA; ${ }^{5}$ Division of Cancer Prevention and Control, National Center for Chronic Disease Prevention and Health Promotion, CDC, Atlanta, Georgia, USA; ${ }^{6}$ US Department of Veterans Affairs, Salt Lake City Healthcare System, Salt Lake City, Utah, USA; ${ }^{7}$ RTI International, Waltham, Massachusetts, USA; ${ }^{8}$ Carter Consulting, Atlanta, Georgia, USA. Correspondence: Katherine Kolor (kkolor@cdc.gov)

The first two authors contributed equally to this work.

Submitted 29 January 2017; accepted 12 June 2017; advance online publication 21 September 2017. doi:10.1038/gim.2017.118 
outcome of ACA coverage of BRCA testing would be an increase in the number of people who pay nothing out of pocket for testing post-ACA implementation compared with preimplementation. Another example is the US Supreme Court decision in June 2013 that invalidated specific BRCA test patents, with a number of other clinical laboratories subsequently offering $B R C A$ testing in the United States. ${ }^{18}$

Understanding how these many factors may, individually and collectively, directly or indirectly, influence $B R C A$ testing rates and costs is complex, and subject to the limitations of available data for assessing use of $B R C A$ testing in the general US population. BRCA genetic testing is not captured currently in any national surveillance system. Medical claims data have been used in a number of studies on general BRCA testing trends among the nation's insured, including guideline-concordant use. For example, a recent study examined trends in BRCA testing in the United States from 2004 to 2014 based on claims data from a single private health insurance provider and found that use of BRCA testing has shifted from primarily patients affected by cancer to unaffected patients. ${ }^{19}$ Other studies have found that clinical use of BRCA testing did not follow current guidelines and remained underutilized. ${ }^{20-22}$

Two recent studies examined the impact of a May 2013 celebrity op-ed ${ }^{12}$ using medical claims data and demonstrated an increase in $B R C A$ testing coinciding with the publicity. However, the increase in BRCA test use was associated with lower utilization of follow-up health services, such as mastectomy, mammography, and magnetic resonance imaging rates among women who had BRCA tests. ${ }^{14,23}$ These types of studies are feasible because $B R C A$ testing can be identified in medical claims using either $B R C A$-specific Healthcare Common Procedure Coding System (HCPCS) billing codes that were introduced beginning in 2001 or genespecific Current Procedural Terminology (CPT) billing codes for BRCA testing introduced in 2012. However, the HCPCS codes used prior to 2013 probably incompletely ascertain $B R C A$ testing, because a portion of $B R C A$ tests were billed using nonspecific molecular diagnostic codes. ${ }^{24}$ Alternative methods and data sources are needed to reliably and comprehensively capture those tests.

We examined trends in utilization, median total payment (to a provider), and expected patient out-of-pocket (OOP) payments for BRCA testing from 2003 to 2014 in a large commercially insured population. We compared our findings with estimated rates of $B R C A$ testing based on reported revenue from Myriad Genetics (Salt Lake City, UT), the presumed sole provider of BRCA testing through June 2013. We describe $B R C A$ testing trends over this time period by patient age, geographic region, and codes for personal or family history of breast or ovarian cancer.

\section{MATERIALS AND METHODS}

Twelve years of claims data from 2003 through 2014 for women aged 18-64 years were extracted from Truven Health Analytics MarketScan Commercial Claims and Encounters
(CCAE) databases. ${ }^{25}$ The number of women enrollees aged 18-64 years included in the analyses ranged from as low as 6.2 million in 2006 to as high as 20.6 million in 2012, including capitated and noncapitated plans and partial-year enrollment. The MarketScan CCAE databases contain enrollment data for adults and dependent children with employer-sponsored health insurance and longitudinally linked utilization and payment data for inpatient, outpatient, and laboratory services for those same individuals. MarketScan claim and patient-level information, including age, sex, geographic location, diagnostic codes, procedure codes, and total allowable charges (health plan payments, expected OOP payment), were analyzed. We adjusted the payment variables to 2014 purchasing power parity values using the Personal Consumption Expenditures index. ${ }^{26}$

$B R C A$ tests were ascertained from both outpatient and inpatient claims. Claims of BRCA testing were extracted using HCPCS codes S3818-S3823 and CPT codes 81211-81217 (Supplementary Table S1 online). To increase the specificity of our study, we excluded BRCA testing ordered under nonspecific molecular diagnostic CPT codes from our analysis. Medical claims data will not ascertain $B R C A$ testing done as self-pay. We defined four subtypes of $B R C A$ tests based on billing codes: full-gene sequencing, known familial variant, Ashkenazi panel, and large rearrangement tests (Supplementary Table S1).

The annual calendar year utilization rates of any BRCA test and subtypes were calculated as the number of women enrollees aged 18-64 years who had at least one claim in that calendar year that contains one of the BRCA testing procedure codes divided by the total number of women aged 18-64 years enrolled at any point during that year, times 100,000. For each study year, enrollee age was defined as the age on January 1 or at the start of enrollment period for partial year enrollees. Rates were also calculated by age group (ages 18-34, 35-44, 45-54, and 55-64 years), and by United States census region (Northeast, Midwest, South, and West).

We used median total payment to approximate the average payment for BRCA tests as it is less influenced by outliers and negative values that were used to adjust erroneous coding, as in credits to offset duplicate payments. Total payment is the total gross payment to providers for a specific service. It is the amount eligible for payment after applying pricing guidelines such as fee schedules and discounts but before applying deductibles, copayments, and coordination of benefits. ${ }^{25}$ Claims with zero payments account for a small percentage of the sample and were removed from median total and OOP payment calculations because these can reflect records added by Truven Health Analytics to adjust for nonfinancial coding errors, some claims from capitated plans, bundled payments for episodes of care in noncapitated plans, or enrollees with another payment source that was not recorded. Patient outof-pocket payments were calculated as the sum of copayment, coinsurance, and deductible payments for each claim.

We grouped cases into four diagnosis groups: (i) newly diagnosed breast or ovarian cancer (incident), (ii) previously 
diagnosed breast or ovarian cancer (nonincident), (iii) family history of breast cancer or ovarian cancer, and (iv) others (Supplementary Table S2). We acknowledge that family history and personal history may not be reliably recorded or categorized. Within each subcategory, we examined the percentage of the enrollees who had zero OOP payments.

$B R C A$ testing revenues aggregated over each calendar year were obtained from quarterly and annual reports filed with the US Securities and Exchange Commission by Myriad Genetics. ${ }^{27}$ Additional BRCA testing providers entered the market beginning in June 2013; however, we did not capture those revenues in our estimates. BRCA testing rates based on revenue were calculated for each year during the study period using the MarketScan median total payment for any $B R C A$ test and US Census estimates for women 18-64 years old. We adjusted revenues to $90 \%$ to account for BRCA testing in the 65 and over group, which we estimate to be about $10 \%$ based on the current study and 2013 Medicare data. ${ }^{28}$ Additional assumptions are described in the Supplementary Methods and Supplementary Table S3.

\section{RESULTS}

Trends in BRCA testing utilization 2003-2014

$B R C A$ testing rates, whether estimated from claims or revenues, exhibited higher overall growth rates during 2003-2009 compared with 2010-2014. From 2003 to 2009, the growth in BRCA testing rates using HCPCS codes in claims data was six times as rapid as the growth in the revenue data (Figure 1a; Supplementary Table S3). During 2010 to 2012 the growth in testing rates was similar between the two sources. From 2012 to 2014, the percentage of women with employer-sponsored insurance who underwent $B R C A$ testing increased by $68 \%$, whereas revenue estimates increased $12 \%$.

Rates of utilization of any BRCA test in MarketScan CCAE databases increased from 2.68 per 100,000 in 2003 to 240.99 per 100,000 in 2014 in women aged 18-64 years (Figure 1b; Supplementary Table S4). In 2013, BRCA testing rates based on claims data increased by $57 \%$, relative to 2012 levels, compared to annual increases of $9 \%, 10 \%$, and $13 \%$ over the preceding 3 years, and 7\% the following year. Most (70\%) of the observed increase in BRCA testing rates in 2013 occurred during April through June (Supplementary Figure S1). Annualized BRCA testing rates per 100,000 for selected months in 2013 are: 202.9 (March), 236.2 (April), 293.7 (May), 306.8 (June), and 296.4 (July).

More than 193,000 women-years of BRCA testing were identified from medical claims. Among women who had any $B R C A$ test, $90 \%$ had full-gene sequencing tests, with percentages increasing over the study period from $86 \%$ in 2003 to $93 \%$ in 2014. Known variants and Ashkenazi panel testing each accounted for $5 \%$ of women who had BRCA tests, with the percentages for each decreasing from $7 \%$ in 2003 to $4 \%$ in 2014 (Supplementary Table S4). Large rearrangement tests showed a rapid increase from 46.69 per 100,000 in 2012 to 208.24 per 100,000 in 2014 , performed in $86 \%$ of women who had $B R C A$ tests in 2014. The average number of $B R C A$ a
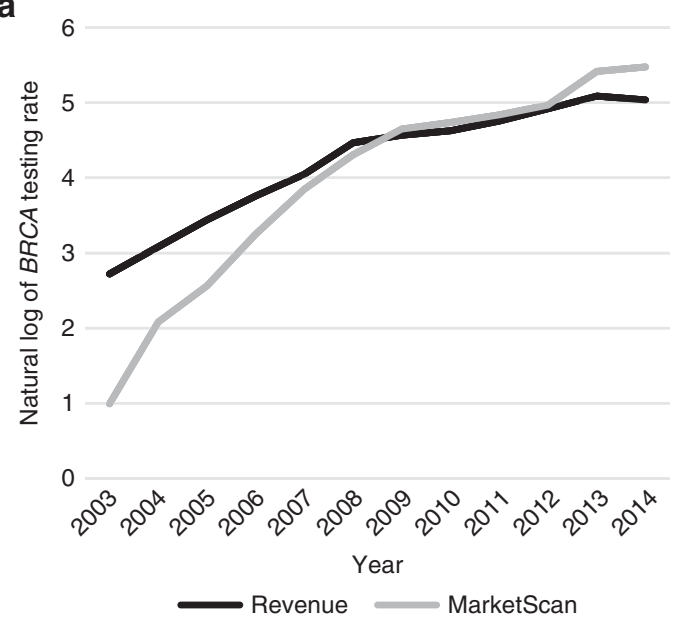

b

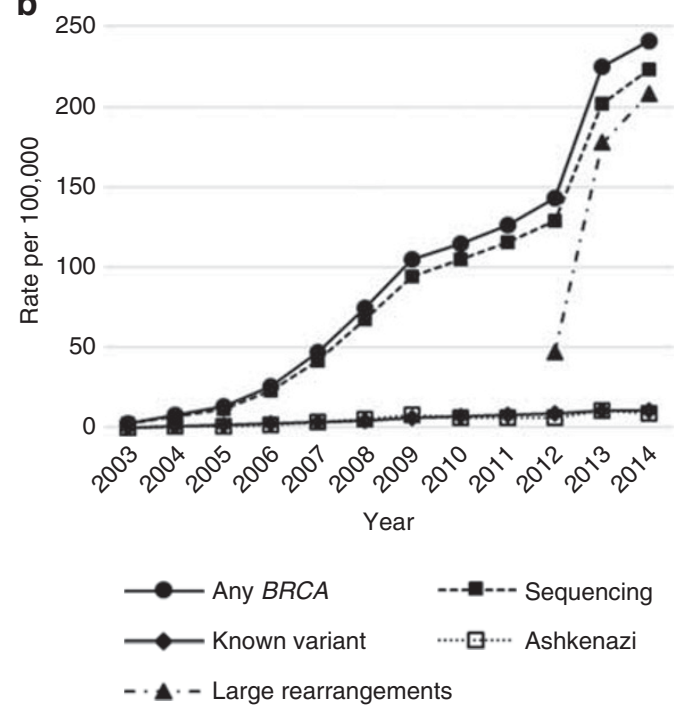

Figure 1 Rates of BRCA tests and subtypes per 100,000 women aged 18-64 years: MarketScan and revenue estimates. (a) Growth in BRCA testing rates among women aged 18-64 years per 100,000, MarketScan CCAE databases versus revenue estimates, 2003-2014. (b) Utilization rates of any BRCA test and subtypes among women aged 1864 years, 2003-2014 (per 100,000 MarketScan CCAE databases enrollees). Subtypes include full-gene sequencing, known variant, Ashkenazi panel, and large rearrangement tests.

testing claims among women remained stable at about 1.1 during 2004-2011, consistent with each woman having about one BRCA test on average. The average number of BRCA testing claims increased to 1.5 in 2012, and then to 1.9 in 2013 and 2014, consistent with more women having two claims for $B R C A$ test subtypes with the implementation of a specific billing code for large rearrangement tests.

\section{$B R C A$ testing trends by age group}

The highest rates of $B R C A$ testing occurred among women aged 45-54 years, and the lowest rates were among women aged 18-34 years (Figure 2a; Supplementary Table S5). The 


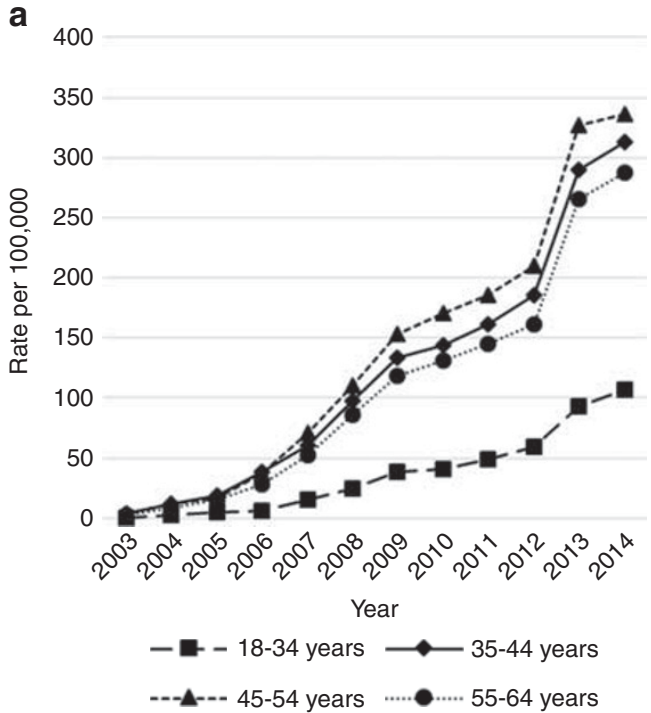

b

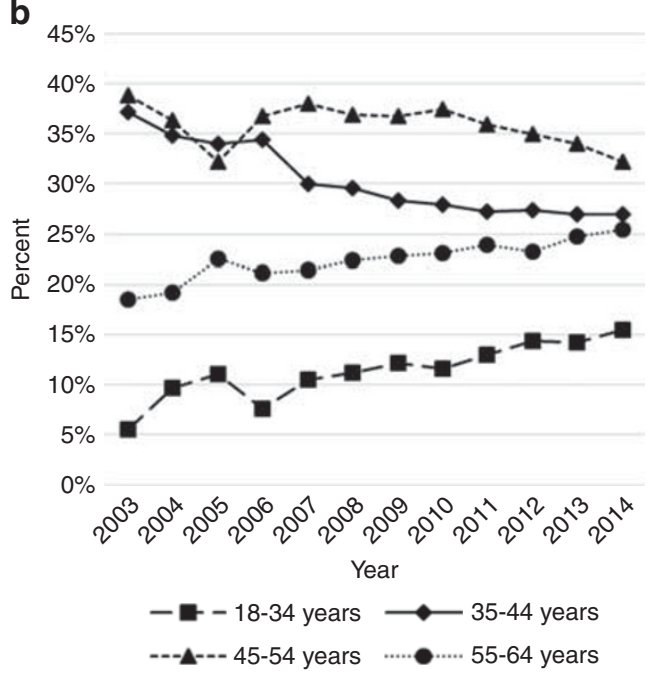

Figure 2 Rates of $B R C A$ testing by age group per 100,000 women aged 18-64 years, MarketScan CCAE databases, 2003-2014. (a) $B R C A$ test rates (per 100,000 enrollees) among women by age group: 18-34 years, 35-44 years, 45-54 years, 55-64 years. (b) Percent of BRCA testing among women by age group, 2003-2014.

proportions of $B R C A$ testing occurring in the youngest (18-34 years) and oldest (55-64 years) age groups increased over the study period (Figure 2b; Supplementary Table S5).

\section{Diagnosis codes associated with BRCA testing}

From 2003-2012 more BRCA testing was performed in women with diagnosis codes indicative of a personal history of breast or ovarian cancer (newly and previously diagnosed) compared with a family history of these cancers (Figure 3; Supplementary Table S6). However, beginning in 2007, family history accounted for an increasing proportion of women with $B R C A$ tests compared with personal history. Starting in 2013, BRCA testing with diagnosis codes indicative of a family history of cancer exceeded testing associated with

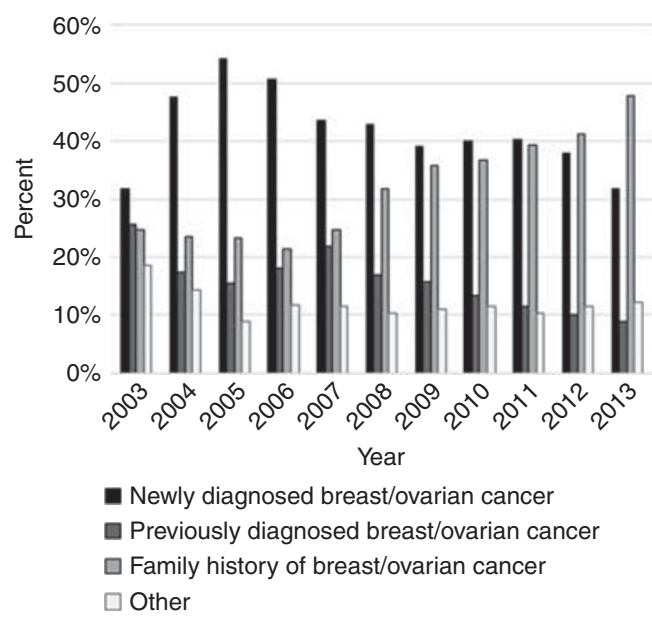

Figure 3 Percent of BRCA testing among women aged 18-64 years by personal or family history of breast or ovarian cancer, MarketScan CCAE databases, 2003-2014. Women with any BRCA test stratified by diagnosis groups: newly diagnosed breast or ovarian cancer (incident), previously diagnosed breast or ovarian cancer (nonincident), family history of breast or ovarian cancer, and other.

personal history of breast cancer or ovarian cancer $(47.9 \%$ versus $40.7 \%)$.

\section{Trends in BRCA testing payments and OOP costs, 2003-2014}

Median claim-level payment remained relatively stable over the study period for all BRCA test subtypes; however, median patient-level payment for any BRCA test increased in 2013 from $\$ 3,130$ to $\$ 3,585$, consistent with increased patient-level costs following the implementation of a specific billing code for large rearrangement tests (Figure 4a; Supplementary Table S7). Among women who had any BRCA test, the proportion of women with zero OOP payments decreased from $78 \%$ in 2005 to $63 \%$ in 2012 , then increased to $71 \%$ and 80\% in 2013 and 2014, respectively (Figure 4a; Supplementary Table S7). Women with diagnosis codes indicating a family history of breast or ovarian cancer exhibited a greater relative increase in zero OOP expenses in 2012-2014 compared with those with previously diagnosed personal history of breast or ovarian cancer (45\% versus 27\%) (Figure $4 \mathbf{b}$; Supplementary Table S8).

\section{Geographic distribution of $B R C A$ testing}

$B R C A$ testing rates were highest in the Northeast region throughout the study period (Figure 5a,b; Supplementary Table S9). Although the regional gaps in relative testing rates generally decreased over the study period (Figure $5 \mathbf{b}$ ), the Northeast region exhibited the greatest increase in 2013 relative to 2012 (78.6\%). In 2014, BRCA testing rates dropped in the Northeast, but continued to increase in the other regions. 
a

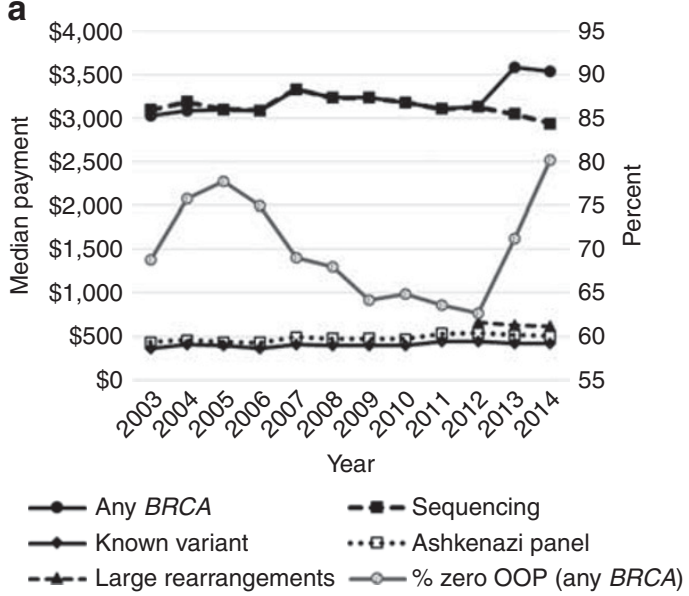

b

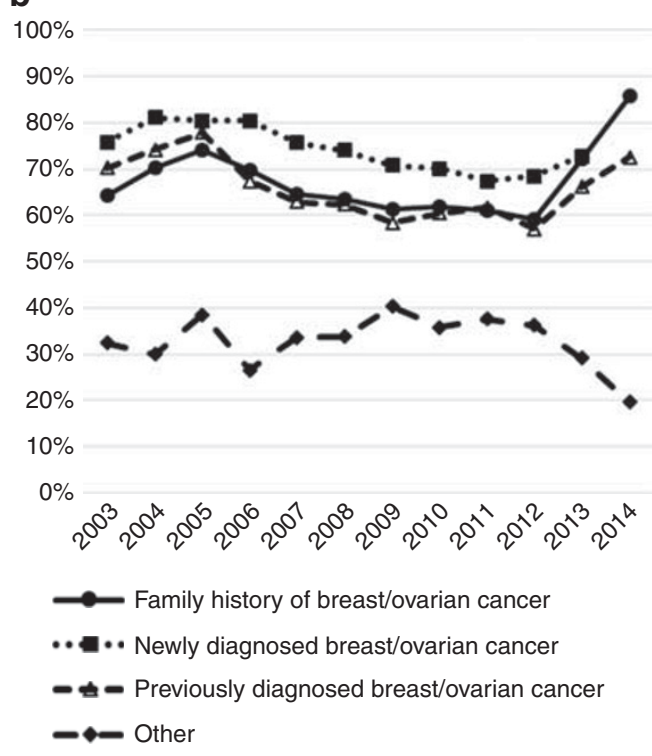

Figure 4 Costs of BRCA test and subtypes, MarketScan CCAE databases, 2003-2014. (a) Total payment to provider amount per enrollee for $B R C A$ test and subtypes, and percentage of enrollees with zero out-of-pocket payment for any BRCA test (right axis). Subtypes include full-gene sequencing, known variant, Ashkenazi panel, and large rearrangement tests. (b) Percentage of zero out-of-pocket payment among women by diagnosis group: family history of breast or ovarian cancer, newly diagnosed breast or ovarian cancer (incident), previously diagnosed breast or ovarian cancer (nonincident), other. OOP, out of pocket.

\section{DISCUSSION}

The difference in growth rates in apparent $B R C A$ testing rates observed between the revenue and MarketScan data sources from 2003 to 2009 most likely reflects increasing use of HCPCS codes and decreasing use of nonspecific molecular diagnostic CPT codes as a proportion of all BRCA testing billing codes, and perhaps a decreasing proportion of self-paid $B R C A$ tests. That is, although the claims data underperform the revenue data in capturing $B R C A$ testing during this period, there was increasing convergence over time. The similar rates of growth in BRCA testing from 2010 through
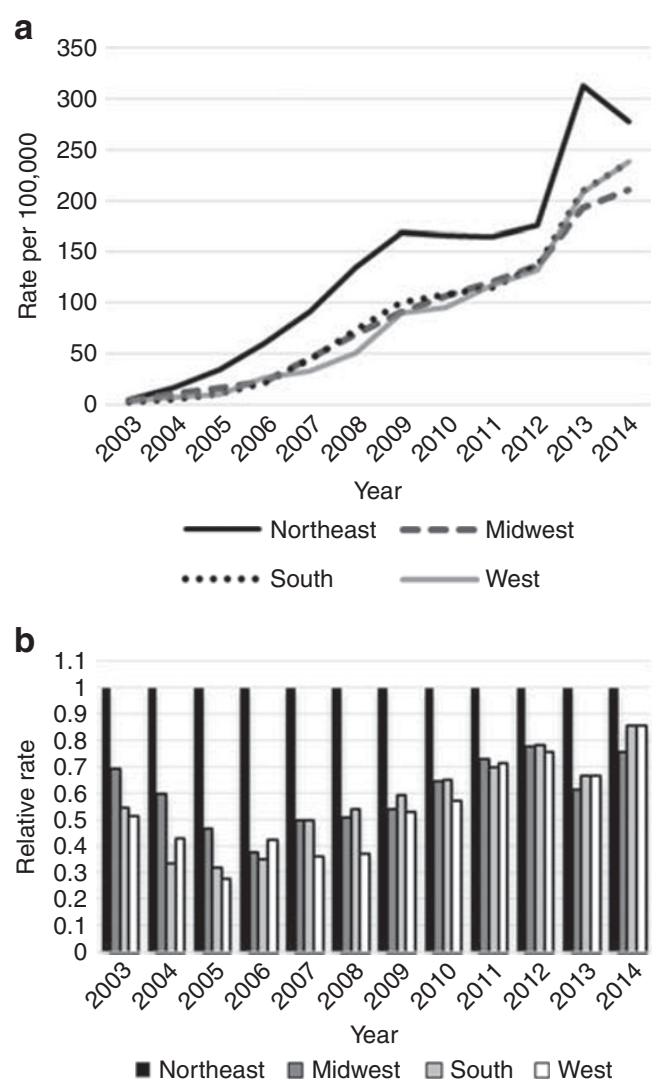

Figure 5 Regional BRCA test rates and relative rates per 100,000 women aged 18-64 years, MarketScan CCAE databases 2003-2014. (a) BRCA test rates by geographic region: Northeast, Midwest, South, West. (b) Relative BRCA test rates by geographic region, compared with Northeast region. Northeast: Connecticut, Maine, Massachusetts, New Hampshire, Rhode Island, Vermont, New Jersey, New York, Pennsylvania. Midwest: Illinois, Indiana, Michigan, Ohio, Wisconsin, lowa, Kansas, Minnesota, Missouri, Nebraska, North Dakota, South Dakota. South: Delaware, District of Columbia, Florida, Georgia, Maryland, North Carolina, South Carolina, Virginia, West Virginia, Alabama, Kentucky, Mississippi, Tennessee, Arkansas, Louisiana, Oklahoma, Texas. West: Arizona, Colorado, Idaho, Montana, Nevada, New Mexico, Utah, Wyoming, Alaska, California, Hawaii, Oregon, Washington.

2012 from the two data sources suggest similar level of accuracy in ascertainment during those years.

Beginning in 2013, claims data are expected to capture a higher proportion of $B R C A$ tests due to the introduction of specific CPT codes for BRCA testing and the elimination of certain nonspecific billing codes. Additionally, claims data are expected to outperform the revenue data examined in this study in ascertaining BRCA testing starting in mid-2013 given the US Supreme Court decision in June 2013 that cleared the way for other laboratories to enter the market. Indeed, $B R C A$ testing rates based on medical claims grew at a substantially faster rate than revenues during 2013-2014.

The rate of any BRCA testing among women increased by $57 \%$ in 2013, compared with average annual increases of $11 \%$ in the 3 preceding years. The timing of the increase in $B R C A$ testing during April-June 2013 coincided with publication of a New York Times op-ed on 14 May 2013, and was 
geographically concentrated in the Northeast region. ${ }^{12}$ These findings are consistent with a recently published analysis of MarketScan CCAE data that showed that the increase in BRCA testing during 2013 occurred within a 15-day period following the publication of the op-ed, and the increase was sustained throughout 2013. ${ }^{14}$ In addition, the Centers for Medicare \& Medicaid Services issued a policy implementing specific molecular diagnostic CPT codes and eliminating nonspecific billing codes, effective on 1 January 2013, and implemented 1 April 2013. ${ }^{29}$ Our results show a 16\% increase in BRCA testing occurring during the month of April 2013, prior to publication of the op-ed, which could reflect in part the implementation of this policy.

The 2013 increase in BRCA testing also followed a February 2013 ACA clarification that BRCA testing, as well as counseling, was a covered preventive service for women whose family history is associated with an increased risk for deleterious mutations in the BRCA1 or BRCA2 genes. ${ }^{17}$ Notably, we observed a reversal of a trend toward decreasing proportions of women with zero OOP costs, with a $28 \%$ relative increase from 2012 to 2014 for all women who had $B R C A$ tests, and a $45 \%$ increase for $B R C A$ testing based on family history. The remaining $14 \%$ with positive OOP among those tested based on family history may be due to various reasons including that "grandfathered" plans were exempt from the preventive services provision of the ACA-in 2015, about $25 \%$ of workers covered in employer-sponsored insurance were enrolled in grandfathered plans ${ }^{30}$-or, because the family history did not meet USPSTF criteria as required by the ACA.

The steady increase in the proportion of BRCA testing associated with a diagnosis code of family history of breast or ovarian cancer observed starting in 2007 is consistent with the findings of Guo et al. ${ }^{19}$ This shift occurred in the context of the 2005 USPSTF BRCA recommendation, which promoted referral for BRCA counseling of unaffected women based on family history risk assessment. The USPSTF recommendation is notable as the first $B R C A$ recommendation intended for primary care providers, whereas the earlier $B R C A$ recommendations were targeted toward specialists in medical genetics and oncology. The shift also occurred in the context of regional direct-to-consumer advertising campaigns for BRCA testing services during 2007-2011. 27,31,32

The median yearly payment per enrollee tested was fairly level at about $\$ 3,100$ until 2013 when it increased to $\$ 3,585$. That increase probably reflects the introduction of a specific CPT code for large rearrangement test billing in 2012 and the incorporation of large rearrangement testing into clinical guidelines. Indeed, the average number of claims for each enrollee, which had been stable at about 1.1 during 20042012, increased to 1.5 in 2012, and then to 1.9 in 2013 and 2014. That increase is consistent with the use of large rearrangement tests as a reflex test when $B R C A$ sequencing tests are negative.

This study has several strengths. The MarketScan CCAE databases include a large number of clinical encounter records, with 18.6 million women enrollees aged 18-64 in 2014 , which accounts for about $18 \%$ of US women aged $18-$ 64. Instead of charges, which do not reflect the true costs of BRCA tests, the MarketScan CCAE databases have the actual amounts paid by health plans and the residual amounts expected from patients. We compared the overall observed trends in BRCA testing rates over the study period with revenue data. We limited our MarketScan analysis to specific $B R C A$ billing codes.

The study has several limitations. MarketScan CCAE databases include women who have employer-sponsored insurance, but not those who are not insured, have public insurance, or purchase insurance themselves. The sample is not nationally representative of the population with employer-sponsored insurance or the general US population. The number of plans and enrollees in the MarketScan CCAE databases available to the researchers varied over the study period, generally increasing until 2013, when a drop in the number of enrollees was observed, including a $17 \%$ decrease in women enrollees aged 18-64 years relative to 2012 . We do not adjust for women who had BRCA testing in multiple years of the study; however, we estimate that these represent less than $1 \%$ of women who had BRCA testing (unpublished results). The MarketScan analysis does not capture BRCA tests ordered under nonspecific molecular diagnostic CPT codes or those self-paid; however, the revenue analysis should capture these tests until June 2013. The analyses do not examine whether the BRCA testing that occurred was in accordance with clinical guidelines. The reliability of the coding of BRCA tests may have evolved over time, which could have impacted the completeness of ascertainment of $B R C A$ tests, particularly prior to $2013 .^{22,24} \mathrm{We}$ are limited by the nature of the claims data, which involves recording errors, adjudication, and other factors. Neither the MarketScan nor the Myriad revenue analyses would detect if other laboratories aside from Myriad offered BRCA testing using nonspecific molecular diagnostic CPT codes.

Observed trends in BRCA testing rates and zero OOP payments in 2003-2014 are consistent with a number of factors expected to influence the uptake of $B R C A$ testing, including clarification of full coverage of $B R C A$ testing for many people under the ACA, the US Supreme Court decision invalidating certain BRCA gene patents, clinical guidelines, advertising, and celebrity publicity. This study is unique in its ability to track trends in rates of genetic testing for BRCA in the United States for specific demographic groups prior to 2012-2013. However, this analysis was not able to track the extent to which the increased uptake of $B R C A$ testing was targeted to women at elevated risk, or that it resulted in increased uptake of preventive services among women who found that they had a BRCA mutation. A comprehensive analysis of the likely population health impact of increased uptake of $B R C A$ testing is needed but may require additional sources of data. Assessment of trends in rates of genetic testing for other genes or conditions, such as Lynch syndrome, also remains challenging. 


\section{SUPPLEMENTARY MATERIAL}

Supplementary material is linked to the online version of the paper at http://www.nature.com/gim

\section{ACKNOWLEDGMENTS}

The findings and conclusions in this report are those of the authors and do not necessarily represent the official position of the Centers for Disease Control and Prevention or the Veterans Health Administration.

\section{DISCLOSURE}

The authors declare no conflict of interest.

\section{REFERENCES}

1. Moyer VA. Risk assessment, genetic counseling, and genetic testing for BRCA-related cancer in women: U.S. Preventive Services Task Force recommendation statement. Ann Intern Med. 2014;160:271-281.

2. National Comprehensive Cancer Network. Clinical practice guidelines in oncology. Geneticfamilial high risk assessment: breast and ovarian. 2016. http://www.nccn.org/professionals/physician_gls/pdf/genetics_screening.pdf. Accessed 29 August 2016.

3. US Food and Drug Administration. FDA approves Lynparza to treat advanced ovarian cancer. 2014. http://www.fda.gov/NewsEvents/Newsroom/ PressAnnouncements/ucm427554.htm. Accessed 25 July 2016.

4. Robson ME, Bradbury AR, Arun B, et al. American Society of Clinical Oncology policy statement update: genetic and genomic testing for cancer susceptibility. J Clin Oncol. 2015;33:3660-3667.

5. Berliner JL, Fay AM, Cummings SA, Burnett B, Tillmanns T. NSGC practice guideline: risk assessment and genetic counseling for hereditary breast and ovarian cancer. J Genet Couns. 2013;22:155-163.

6. Balmana J, Diez O, Rubio I, Castiglione M, Group EGW. BRCA in breast cancer: ESMO clinical practice guidelines. Ann Oncol. 2010;21(suppl 5): v20-22.

7. American College of Obstetricians Gynecologists. ACOG practice bulletin no. 103: hereditary breast and ovarian cancer syndrome. Obstet Gynecol. 2009;113:957-966.

8. Lancaster JM, Powell CB, Kauff ND, et al. Society of Gynecologic Oncologists Education Committee statement on risk assessment for inherited gynecologic cancer predispositions. Gynecol Oncol. 2007;107: 159-162.

9. Hampel $H$, Bennett RL, Buchanan A, et al. A practice guideline from the American College of Medical Genetics and Genomics and the National Society of Genetic Counselors: referral indications for cancer predisposition assessment. Genet Med. 2015;17:70-87.

10. American Society of Breast Surgeons. Position statement on BRCA genetic testing for patients with and without breast cancer. 2012. https://www. breastsurgeons.org/new_layout/about/statements/PDF_Statements/BRCA_ Testing.pdf. Accessed 25 July 2016.

11. Howlader $\mathrm{N}$, Noone $\mathrm{AM}$, Krapcho $\mathrm{M}$, et al. SEER cancer statistics review, 1975-2012. http://seer.cancer.gov/csr/1975_2012/browse_csr. php?sectionSEL $=4$ \&pageSEL $=$ sect_04_table.17.html.

12. Jolie A. My medical choice. New York Times, 14 May 2014. http://www. nytimes.com/2013/05/14/opinion/my-medical-choice.html?_r $r=0$.

13. Evans DG, Barwell J, Eccles DM, et al. The Angelina Jolie effect: how high celebrity profile can have a major impact on provision of cancer related services. Breast Cancer Res. 2014;16:442.

14. Desai S, Jena AB. Do celebrity endorsements matter? Observational study of BRCA gene testing and mastectomy rates after Angelina Jolie's New York Times editorial. BMJ. 2016;355:i6357.
15. Patient Protection and Affordable Care Act, 42 U.S.C. Sect. 18001. (2010).

16. US Department of Health and Human Services. Preventive Services Covered Under the Affordable Care Act. http://www.hhs.gov/healthcare/facts/ factsheets/2010/07/preventive-services-list.html. Accessed 22 July 2016.

17. Department of Labor. FAQs about Affordable Care Act implementation (part XII). 2013. https://www.dol.gov/sites/default/files/ebsa/about-ebsa/ our-activities/resource-center/faqs/aca-part-xii.pdf. Accessed 13 January 2017.

18. Cook-Deegan R, Niehaus A. After Myriad: Genetic testing in the wake of recent Supreme Court decisions about gene patents. Curr Genet Med Rep. 2014;2:223-241.

19. Guo F, Hirth JM, Lin YL, et al. Use of BRCA mutation test in the U.S. 2004-2014. Am J Prev Med. 2017;52:702-709.

20. Levy DE, Byfield SD, Comstock CB, et al. Underutilization of BRCA1/2 testing to guide breast cancer treatment: black and Hispanic women particularly at risk. Genet Med. 2011;13:349-355.

21. Armstrong J, Toscano $\mathrm{M}$, Kotchko $\mathrm{N}$, et al. Utilization and outcomes of BRCA genetic testing and counseling in a national commercially insured population: the ABOUT study. JAMA Oncol. 2015;1: $1251-1260$

22. Wright JD, Chen $\mathrm{L}$, Tergas $\mathrm{Al}$, et al. Underuse of BRCA testing in patients with breast and ovarian cancer. Am J Obstet Gynecol. 2016;214: 761-763.

23. Roberts MC, Dusetzina SB. The effect of a celebrity health disclosure on demand for health care: trends in BRCA testing and subsequent health services use. J Community Genet. 2017;8:141-146.

24. Lynch J, Berse B. Methods to identify BRCA testing in claims data. Am J Obstet Gynecol. 2016;215:133-134.

25. Truven Health Analytics. Truven Health MarketScan research databases, commercial claims and encounters, Medicare supplemental, data year 20032014, Ann Arbor, Ml: Truven Health Analytics. http://truvenhealth.com/ markets/life-sciences/products/data-tools/marketscan-databases. Accessed May 31, 2017.

26. Agency for Healthcare Research and Quality. Medical expenditure panel survey: using appropriate price indices for analysis of health care expenditures or income across multiple years. http://meps. ahrq.gov/mepsweb/about_meps/Price_Index.shtml. Accessed 22 July 2016.

27. US Securities and Exchange Commission. EDGAR Search Results: Myriad Genetics. 2016. https://www.sec.gov/cgi-bin/browse-edgar?action = getcompany\&CIK $=0000899923 \&$ owner $=$ exclude \&count $=40 \&$ hidefilings $=0$. Accessed 8 September 2016.

28. Lynch JA, Berse B, Dotson WD, Khoury MJ, Coomer N, Kautter J. Utilization of genetic tests: analysis of gene-specific billing in Medicare claims data. Genet Med. 2017.

29. Centers for Medicare and Medicaid Services. Healthcare Common Procedure Coding System (HCPCS) codes subject to and excluded from Clinical Laboratory Improvement Amendments (CLIA) edits. 2013. https://uww.cms.gov/Outreach-and-Education/Medicare-Learning-NetworkMLN/MLNMattersArticles/Downloads/mm8162.pdf. Accessed 20 April 2017.

30. Kaiser Family Foundation Health Research and Educational Trust. 2015 employer health benefits survey. 2015. http://kff.org/healthcosts/report/2015-employer-health-benefits-survey/. Accessed 22 July 2016.

31. Centers for Disease C, Prevention. Genetic testing for breast and ovarian cancer susceptibility: evaluating direct-to-consumer marketing-Atlanta, Denver, Raleigh-Durham, and Seattle, 2003. MMWR Morb Mortal Wkly Rep. 2004;53:603-606.

32. Direct-to-Consumer Genetic Testing: Business Prospects in the United States. Insight Pharma Reports. http://www.insightpharmareports.com/ uploadedFiles/Reports/Reports/Genetic_Testing/Consumer_Genomics_ sample_pages.pdf. Accessed 30 August 2016. 